Original article

\title{
Relationship between isometric neuromuscular function of the leg extensors with performance tests in basketball
}

\author{
Jelena Ivanović ${ }^{1}$, Milivoj Dopsaj ${ }^{2,3}$, Saša Jakovljević ${ }^{2}$, Milivoje Karalejić ${ }^{2}$ \\ ${ }^{1}$ Serbian Institute of Sport and Sport Medicine, Belgrade, Serbia \\ ${ }^{2}$ Belgrade University, Belgrade, Serbia \\ ${ }^{3}$ South Ural State University, Chelyabinsk, Russia
}

Received 27 April 2018, Revised 13 November 2018, Accepted 28 December 2018

(C) 2018, Ivanović J., Dopsaj M., Jakovljević S., Karalejić M.

(C) 2018, Russian Open Medical Journal

Abstract: The aim of this research was to determine the relationship between the isometric force-time characteristics of the leg extensors and speed and agility performance.

Material and Methods - Sixty young elite basketball players performed a standardized isometric leg press test in order to assess the characteristics of isometric force and 9 field tests in order to assess speed and agility performances.

Results - Based on obtained results, among the measured leg extensors ' force-time characteristics with the observed characteristics of performance tests, the best correlation was in maximal force parameters (from $r=0.370$ to $r=0.610$ with agility and from $r=0.345$ to $r=0.574$ with speed performance) and in rate of force development, measured in time interval of $180 \mathrm{~ms}$, i.e. the characteristic ground contact time during running in submaximal exertion regime, frequent changes of movement direction and vertical rebounds (from $r=0.357$ to $r=0.612$ with agility and from $r=0.320$ to $r=0.468$ with speed performance).

Conclusion - The practical implications of a moderate to strong and consistent correlation between neuromuscular function of the leg extensors and characteristics of performance tests might indicate that improvements in force-time characteristics in young basketball players, may result in significant improvements in speed and change of direction performances longitudinally.

Keywords: rate of force development, speed and agility tests.

Cite as Ivanović J, Dopsaj M, Jakovljević S, Karalejić M. Relationship between isometric neuromuscular function of the leg extensors with performance tests in basketball. Russian Open Medical Journal 2019; 8: e0101.

Correspondence to Jelena Ivanović. Address: Serbian Institute of Sport and Sport Medicine, 72 Kneza Viseslava str., 11030 Belgrade, Serbia. Phone: +381 666410 710. E-mail: jelena.ivanovic@rzsport.gov.rs.

\section{Introduction}

Testing motoric fitness levels of basketball players is an essential component in the evaluation of training programs and the assessment of players' progress during the season [1-5]. Agility and speed are integral aspects of almost every defensive and offensive manoeuvre performed by basketball players during training and games $[2,3,6]$. Both abilities require a rapid switch from eccentric to concentric muscle actions in the leg extensor muscles (stretch-shortening cycle of contraction - SSC). Due to this, adequate preparation of the leg extensors is extremely important, especially in sports such as basketball, which involve different jumping techniques, frequent changes of direction in the frontal and lateral planes, and in sports where muscle force and lower extremity strength have a significant influence on executing different technical and tactical demands $[4,5,7,8]$.

There is a range of studies that have examined relationships between maximal isometric force and speed and agility [8-12]. From the aspect of theory and technology of the training, these types of researches are significant because, based on their results, the conclusions which would indicate the role of force and explosiveness in some sports activities could be gathered. However, most of these studies focused on general characteristics of muscle force and explosiveness, i.e. on maximal values. While performing fast movements of the extremities, it's impossible to achieve absolute values of maximal force at the level of full contractile potential of the engaged muscle. In competitive conditions top level athletes commonly realize movement in the maximal $300 \mathrm{~ms}$ time interval [11, 13-15]. Therefore, all the aspects of directed and specific fitness level should be focused on explosiveness increase (rate of force development - RFD), in the specific time interval in which the movement is realized, i.e. in the early phase of muscle contraction $[4,11,14,16]$. Purposefulness of the results on the athletes fitness level and the development level of tested physical properties, directly depend on applied test and its specific and measuring sensitivity. If the test is more specific in regard to the sports branch, information obtained during the testings is more valid for evaluation the real fitness level $[11,17]$. Despite the attention given to performance assessment by sports professionals and sports scientists, there are not enough 
researches examining the correlation of specific and special characteristics of force-time characteristics of leg extensor within the wide range of various battery of tests for motor skills assessment.

By measuring the isometric force developed by the leg extensors, the force-time curve can also be established $[4,5,7,13$, $14]$, which will differ based on one's ability. Based on analysis of the force-time curve record, the characteristic outgoing values of the system will be obtained, and will directly describe the level of isometric neuromuscular function of leg extensors in each player at 100 and $180 \mathrm{~ms}$ level in the early phase of the contraction (< $200 \mathrm{~ms}$ ), at $250 \mathrm{~ms}$ level and at $50 \%$ of realized maximal force and at $100 \%$ of exerted maximal force in the late phase of the contraction ( $>200 \mathrm{~ms})$. Based on the field motoric test battery [2, $6,18]$, the characteristic outgoing system values will be obtained, and will directly describe level of realized abilities in each examinee in regard to speed and agility in specific motoric activities with or with no ball on the basketball court. Therefore, the main objective of this study is to establish relations between isometric RFD neuromuscular function of leg extensors and speed and agility performance, demonstrated in basic (nonspecific - with no ball) and specific (with ball) conditions with the aim to find and verify better, i.e. more valid and more representative contractile neuromuscular characteristics for better evaluation of the training and fitness level in young basketball players.

\section{Material and Methods}

\section{Participants}

The sample included 60 well trained and healthy Serbian male basketball players who were competing in the Junior and Cadet National team of Serbia. The collected basic anthropomorphological characteristics were as follows: body height $=$ $198.55 \pm 6.58 \mathrm{~cm}$, body mass $=88.14 \pm 11.92 \mathrm{~kg}$, age $=17.67 \pm 1.39$ years, training period $=9.51 \pm 2.07$ years. All tests were conducted in the Laboratory for assessing basic motoric fitness levels and on the basketball court of the First National Training Centre in The Serbian Institute of Sport and Sport Medicine in Belgrade as a regular athletes' check up, using the same procedures and equipment. All athletes were tested over the same period, at the beginning of the main pre-competitive mesocycle. All participants were advised not to engage in strenuous exercise for at least $48 \mathrm{~h}$, nor to eat $2 \mathrm{~h}$ before testing. All tests were performed at 10:00 $\mathrm{am}$. The athletes were tested at the beginning of the competition season in 2012. The study was conducted over a 2-day period. On the first day players underwent anthropometric measurements and isometric leg press strength test. On the second day, speed and agility test were performed.

\section{Laboratory testings}

Maximal isometric force was measured using a leg extension dynamometer (Serbian Institute of Sport and Sport Medicine, Belgrade, Serbia). Subjects were seated on a bench, so that their hip angle was at $110^{\circ}$, knee angle $120^{\circ}$, and ankle angle $90^{\circ}$. After individuals had warmed up for five minutes and received an introduction to the measuring procedure, each participant had two attempts, with one minute of rest between trials. The participants were instructed to exert their maximal force as quickly as possible. In order to assess the contractile characteristics of the isometric muscle force of the leg extensors (bilateral), standardized equipment was used, i.e. a metal device. A foot- platform fixed to the frame by strain-gauge transducers and a standardized "isometric leg press" test was used following the earlier described procedures $[4,5,7,16]$. Data was collected at $2,000 \mathrm{~Hz}$ using interface box with an analog to digital card (National Instruments, Austin, TX, USA). All data were recorded and analyzed using a specially designed software system (M_S_NI, Nikola Tesla Institute, Serbia, Belgrade). Thereafter, data were processed using a personal computer (PC). Maximal isometric force $\left(F_{\max }\right)$ was defined as the highest value of the force $(N)$ recorded during bilateral isometric leg extension. The force-time analysis on the absolute scale included the maximal rate of force development as an indicator of the basic (general) level of $\mathrm{RFD}_{\mathrm{Fmax}}$ expressed in $\mathrm{N} \cdot \mathrm{s}^{-1}$ defined as the greatest increase in force, in a given necessary time, to reach maximal force $[4,5,7,19]$, the indicator of specific isometric leg extensors explosive force or the $S$ gradient of the leg extensors force $\mathrm{RFD}_{50 \%}$, as a rate of force development measured at $50 \%$ of $F_{\max }$, the indicator of special level of leg extensors explosive force development $\mathrm{RFD}_{250 \mathrm{~ms}}$ measured at time zone of SSC, i.e. at $250 \mathrm{~ms}$ of $\mathrm{t}_{\mathrm{Fmax}}[5,19,20]$, the indicator of special level of explosive force development RFD $_{180 \mathrm{~ms}}$ measured at $180 \mathrm{~ms}$ of $\mathrm{t}_{\mathrm{Fmax}}[4,5,20]$, the indicator of special level of explosive force development $\mathrm{RFD}_{100 \mathrm{~ms}}$, measured at $100 \mathrm{~ms}$ of $t_{\text {Fmax }}[15,20]$. All isometric force-time characteristics were analyzed from the aspect of relative values with allometric partialisation, by applying the following procedure $\mathrm{RFD}_{\text {allom }}=$ $\mathrm{RFD} / \mathrm{kgBM}^{0.667}[4,19,21]$.

\section{Basketball court tests}

All athletes performed a thorough warm-up as part of their training routine. This included jogging, ball-skill drills, static stretching, and submaximal sprints. All speed and agility tests were performed on basketball court, and time was measured using Infrared timing gates (Fusion Sport, SmartSpeed with an accuracy of $\pm 0.01 \mathrm{~s}$, Grabba International Pty Ltd., Australia).

$20 \mathrm{~m}$ sprint with and without dribbling. Timing lights were placed at the start, $5 \mathrm{~m}$ (first-step quickness), $15 \mathrm{~m}$ (acceleration), and $20 \mathrm{~m}$ (sprint) in order to collect sprint times over the 3 distances. The starting position was standardized for all subjects. Athletes started in a 2-point crouched position with the left toe approximately $30 \mathrm{~cm}$ back from the starting line and the right toe approximately in line with the heel of the left foot. Athletes performed two repetitions for sprint test and two repetitions for sprint with dribbling test with the best (fastest) times from each used for statistical analysis.

Agility T-Test. The athletes were asked to sprint in a straight line to a cone $9 \mathrm{~m}$ away. Then they had to side shuffle to the left without crossing their feet to another cone $4.5 \mathrm{~m}$ away. After touching the cone, they side shuffled to the right to a third cone 9 $\mathrm{m}$ away. The athletes then side shuffled back to the middle cone, and ran backward to the starting position $[2,6,22] .4$ variables were observed: forward running, lateral running, backward running and total time.

Slalom with and without ball. On the one half of the court 3 cones were placed linear, with the span of $260 \mathrm{~cm}$. Basketball players were standing behind the baseline and on the sign started dribbling with their left arm at maximal speed, and dribbled a basketball between cones passing the ball from one hand to another. Finish line was at the same place as the start, at the baseline. There were two trials with and without the ball and the best one was retained for analysis [23]. 
Table 1. The results of descriptive statistics

\begin{tabular}{|c|c|c|c|c|c|c|}
\hline Parameters & Mean $\pm S D$ & CV\% & Min-Max & & /p) & ICC \\
\hline $\mathrm{F}_{\max }(\mathrm{N})$ & $3941.9 \pm 885.4$ & 22.46 & 2203.4-6208.1 & 0.828 & 0.499 & 0.965 \\
\hline $\mathrm{RFD}_{\text {Fmax }}, \mathrm{N} \cdot \mathrm{s}^{-1}$ & $3070.6 \pm 1138.1$ & 37.07 & $684.6-6808.6$ & 0.966 & 0.308 & 0.891 \\
\hline $\mathrm{RFD}_{50 \%}, \mathrm{~N} \cdot \mathrm{s}^{-1}$ & $10383.3 \pm 4036.9$ & 38.88 & $3227.2-20388.6$ & 0.545 & 0.928 & 0.875 \\
\hline $\mathrm{RFD}_{100 \mathrm{~ms}}, \mathrm{~N} \cdot \mathrm{s}^{-1}$ & $9877.9 \pm 4387.5$ & 44.42 & $3881.8-20941.1$ & 0.776 & 0.584 & 0.800 \\
\hline $\mathrm{RFD}_{180 \mathrm{~ms}}, \mathrm{~N} \cdot \mathrm{s}^{-1}$ & $9983.6 \pm 3709.0$ & 37.15 & 3400.9-18718.9 & 0.601 & 0.863 & 0.851 \\
\hline $\mathrm{RFD}_{250 \mathrm{~ms}}, \mathrm{~N} \cdot \mathrm{s}^{-1}$ & $9299.4 \pm 3103.9$ & 33.38 & $3522.4-17045.7$ & 2.313 & 0.000 & 0.893 \\
\hline$T$ test forward running, $\mathrm{s}$ & $1.950 \pm 0.130$ & 6.68 & $1.765-2.523$ & 0.782 & 0.574 & 0.947 \\
\hline $\mathrm{T}$ test lateral running, $\mathrm{s}$ & $6.053 \pm 0.449$ & 7.41 & $5.279-7.514$ & 0.754 & 0.620 & 0.960 \\
\hline $\mathrm{T}$ test backward running, $\mathrm{s}$ & $2.535 \pm 0.168$ & 6.62 & $2.230-2.990$ & 0.655 & 0.785 & 0.913 \\
\hline $\mathrm{T}$ test total time, $\mathrm{s}$ & $10.537 \pm 0.668$ & 6.34 & $9.425-12.707$ & 0.830 & 0.496 & 0.973 \\
\hline Defensive movements, s & $9.180 \pm 0.615$ & 6.70 & $7.782-11.143$ & 0.946 & 0.333 & 0.941 \\
\hline Slalom, s & $4.201 \pm 0.240$ & 5.71 & $3.843-5.066$ & 0.643 & 0.802 & 0.956 \\
\hline Change of direction, $\mathrm{s}$ & $12.101 \pm 0.707$ & 5.85 & $11.234-14.947$ & 0.930 & 0.352 & 0.957 \\
\hline Change of direction with dribbling, $s$ & $12.654 \pm 0.657$ & 5.19 & $11.507-15.401$ & 0.759 & 0.612 & 0.964 \\
\hline Control of dribbling, $s$ & $13.090 \pm 1.039$ & 7.94 & $11.484-16.707$ & 0.745 & 0.636 & 0.959 \\
\hline Quickness $5 \mathrm{~m}, \mathrm{~s}$ & $1.740 \pm 0.481$ & 27.63 & $0.852-2.453$ & 0.804 & 0.537 & 0.984 \\
\hline Acceleration $15 \mathrm{~m}, \mathrm{~s}$ & $1.312 \pm 0.462$ & 35.19 & $0.928-2.191$ & 0.847 & 0.469 & 0.813 \\
\hline Sprint $20 \mathrm{~m}, \mathrm{~s}$ & $3.052 \pm 0.157$ & 5.16 & $2.765-3.664$ & 0.891 & 0.406 & 0.969 \\
\hline Quickness with dribbling $5 \mathrm{~m}, \mathrm{~s}$ & $1.829 \pm 0.540$ & 29.54 & $0.794-2.990$ & 0.714 & 0.687 & 0.869 \\
\hline Acceleration with dribbling $15 \mathrm{~m}, \mathrm{~s}$ & $1.349 \pm 0.498$ & 36.93 & $0.820-2.277$ & 0.892 & 0.404 & 0.785 \\
\hline Sprint with dribbling $20 \mathrm{~m}$, s & $3.145 \pm 0.256$ & 8.15 & $1.996-4.070$ & 0.965 & 0.309 & 0.852 \\
\hline
\end{tabular}

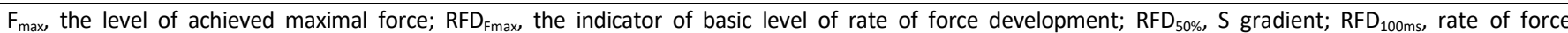
development measured at $100 \mathrm{~ms}$; RFD $180 \mathrm{~ms}$, rate of force development measured at $180 \mathrm{~ms}$; RFD $250 \mathrm{~ms}$, rate of force development measured at 250 ms; Mean $\pm S D$, mean value with standard deviation; Min, minimal variable value; Max, maximum variable value; CV\%, variable coefficient of variation; KS, Kolmogorov-Smirnov test; ICC, intraclass correlation coefficient.
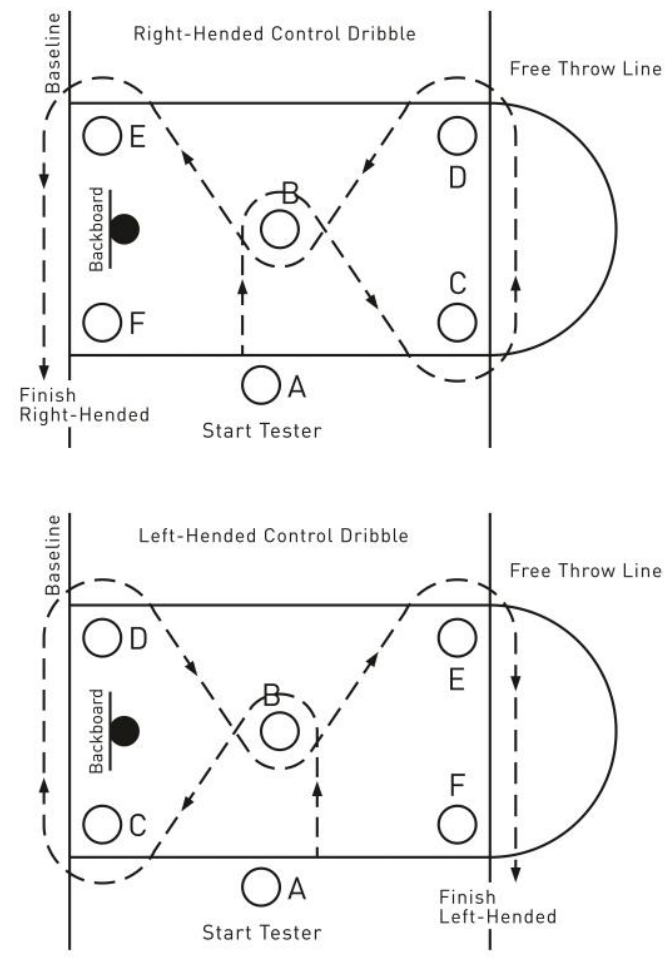

Figure 1. Shematic illustration of the Control of dribbling test.

A, B, C, D, E, F - cones; dotted arrow - direction of dribbling.
Control of dribbling. The athletes were required to navigate a dribbling course defined by six cones within a rectangle measuring $5.8 * 3.6 \mathrm{~m}$ as rapidly as possible [18]. The athletes started with their non-dominant hand on the non-dominant side of cone $A$. They dribbled with non-dominant hand to the non-dominant side of cone $B$, and then proceed to cone $C$ and cone $D$ dribbling with the dominant hand. The course continued with the non-dominant hand to cone $\mathrm{E}$ and then with the dominant hand to cone $\mathrm{F}$ where the test was completed (Figure 1).

Defensive movements. The player was required to slide laterally without crossing the feet in a sequence of seven changes of direction [18]. Whenever the players changed direction, they were required to touch the floor and execute a drop-step (changing direction by moving the trailing foot in the sliding motion to the new direction (Figure 2). Three trials were given for each test. The first was a practice trial and the sum of the second and third trials was retained for analysis.

Change of direction with and without dribbling. This test consists of a sprint with several changes of direction. The athletes started from a standing position behind the baseline and ran maximal speed to 2 different lines: the near free-throw line $(5.8 \mathrm{~m})$ and the half-court line. As they arrived at each line, they sprinted back to the original baseline. Athletes performed two repetitions for sprint test and two repetitions for sprint with dribbling while running the whole distance. Two players performed the test at the same time to encourage maximal effort. Trial with the best (fastest) times was used for statistical analysis [2, 23]. 
Table 2. Relation between neuromuscular function of leg extensors and agility performance

\begin{tabular}{|c|c|c|c|c|c|c|}
\hline & $F_{\max }$ & $\mathrm{RFDF}_{\max }$ & $\mathrm{RFD}_{50 \%}$ & $\mathrm{RFD}_{100 \mathrm{~ms}}$ & $\mathrm{RFD}_{180 \mathrm{~ms}}$ & $\mathrm{RFD}_{250 \mathrm{~ms}}$ \\
\hline$T$ test forward running & $-0.496 * *$ & $-0.499 * *$ & $-0.449 * *$ & $-0.359 * *$ & $-0.506 * *$ & -0.165 \\
\hline $\mathrm{T}$ test lateral running & $-0.557^{* *}$ & $-0.501 * *$ & $-0.547^{* *}$ & $-0.453^{* *}$ & $-0.612^{* *}$ & $-0.320^{*}$ \\
\hline $\mathrm{T}$ test backward running & $-0.370 * *$ & $-0.261^{*}$ & $-0.329 *$ & -0.241 & $-0.357^{* *}$ & -0.174 \\
\hline T test & $-0.567 * *$ & $-0.503 * *$ & $-0.541^{* *}$ & $-0.437 * *$ & $-0.604^{* *}$ & $-0.294^{*}$ \\
\hline Defensive movements & $-0.517 * *$ & $-0.531 * *$ & $-0.451^{* *}$ & $-0.374 * *$ & $-0.510 * *$ & -0.242 \\
\hline Slalom & $-0.431 * *$ & $-0.425 * *$ & $-0.454 * *$ & $-0.397 * *$ & $-0.493 * *$ & -0.136 \\
\hline Slalom with dribbling & $-0.430 * *$ & $-0.442 * *$ & $-0.424 * *$ & $-0.356 * *$ & $-0.473^{* *}$ & -0.212 \\
\hline Change of direction & $-0.519 * *$ & $-0.408 * *$ & $-0.396 * *$ & $-0.341 * *$ & $-0.453^{* *}$ & -0.171 \\
\hline Change of direction with dribbling & $-0.610 * *$ & $-0.499 * *$ & $-0.479 * *$ & $-0.401 * *$ & $-0.545^{* *}$ & -0.195 \\
\hline Control of dribbling & $-0.568 * *$ & $-0.584 * *$ & $-0.472 * *$ & $-0.353^{* *}$ & $-0.520 * *$ & $-0.305^{*}$ \\
\hline
\end{tabular}

Data presented as Pearson correlation coefficient. * $\mathrm{p}<0.05 ; * \mathrm{p}<0.01$.

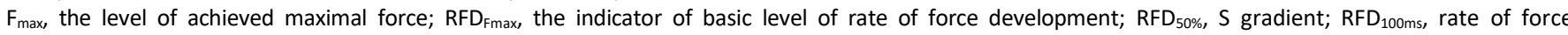
development measured at $100 \mathrm{~ms} ; \mathrm{RFD}_{180 \mathrm{~ms}}$, rate of force development measured at $180 \mathrm{~ms}$; RFD $250 \mathrm{~ms}$, rate of force development measured at 250 ms.

Table 3. Relation between neuromuscular function of leg extensors and speed performance

\begin{tabular}{|c|c|c|c|c|c|c|}
\hline & $\mathrm{F}_{\max }$ & $\mathrm{RFD}_{\mathrm{Fmax}}$ & $\mathrm{RFD}_{50 \%}$ & $\mathrm{RFD}_{100 \mathrm{~ms}}$ & $\mathrm{RFD}_{180 \mathrm{~ms}}$ & $\mathrm{RFD}_{250 \mathrm{~ms}}$ \\
\hline Quickness 5m & $-0.345^{* *}$ & -0.207 & $-0.268^{*}$ & -0.165 & $-0.320^{*}$ & -0.017 \\
\hline Acceleration $15 \mathrm{~m}$ & $-0.574 * *$ & $-0.419 * *$ & $-0.416^{* *}$ & $-0.319 *$ & $-0.468 * *$ & -0.114 \\
\hline Sprint $20 \mathrm{~m}$ & $-0.544^{* *}$ & $-0.379 * *$ & $-0.402 * *$ & $-0.291 *$ & $-0.460 * *$ & -0.086 \\
\hline Acceleration with dribbling $15 \mathrm{~m}$ & $-0.455^{* *}$ & $-0.449 * *$ & $-0.349 * *$ & -0.232 & $-0.400 * *$ & -0.182 \\
\hline Sprint with dribbling $20 \mathrm{~m}$ & $-0.495 * *$ & $-0.462^{* *}$ & $-0.412^{* *}$ & $-0.318^{*}$ & $-0.458^{* *}$ & -0.211 \\
\hline
\end{tabular}

Data presented as Pearson correlation coefficient. *p<0.05; **p<0.01.

$F_{\max }$, the level of achieved maximal force; RFD $\mathrm{Fmax}_{\text {, }}$ the indicator of basic level of rate of force development; $\mathrm{RFD}_{50 \%}, \mathrm{~S}$ gradient; $\mathrm{RFD}_{100 \mathrm{~ms}}$, rate of force development measured at $100 \mathrm{~ms} ; \mathrm{RFD}_{180 \mathrm{~ms}}$, rate of force development measured at $180 \mathrm{~ms} ; \mathrm{RFD}_{250 \mathrm{~ms}}$, rate of force development measured at 250 ms.

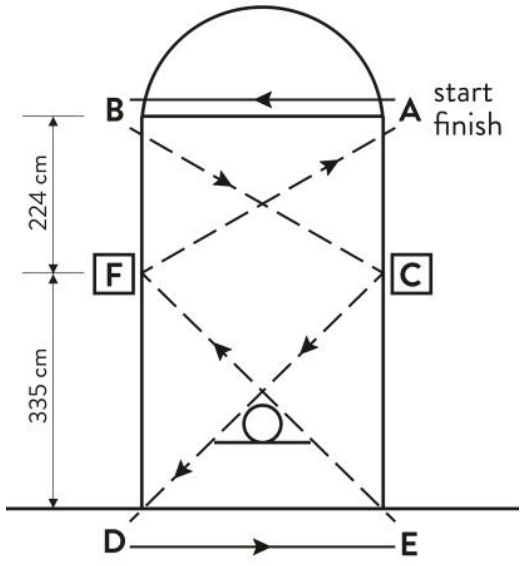

Figure 2. Shematic illustration of the Defensive movements test.

A, B, C, D, E, F - cones; dotted arrow - direction of movements.

\section{Statistical analysis}

Raw results were processed using descriptive statistical analysis in order to calculate basic descriptive statistical values. In order to test the order normality, the nonparametric KolmogorovSmirnov test was used. The reliability of the applied test was defined by use of intraclass correlation coefficient (ICC). Raw results were processed using Pearson correlation coefficient to describe relationships between variables. Statistical significance for all analyses was defined by $p<0.001$. To express a qualitative inference of the magnitude of correlations in subsequent discussion the following scale was used: trivial $(0.0-0.1)$, low $(0.1-$ $0.3)$, moderate $(0.3-0.5)$, strong $(0.5-0.7)$, very strong $(0.7-0.9)$, or practically perfect $(0.9-1.0)$ [24]. All statistical operations were carried out by applying the Microsoft Office Excel 2007 (Microsoft, USA) and the SPSS for Windows, Release 17.0 (SPSS Inc., USA).

\section{Results}

Table 1 shows the descriptive statistics of muscle force-time characteristic and performance tests data.

The results of relation between neuromuscular function of leg extensors and speed and agility performance are presented in Tables 2 and 3.

From the aspect of absolute isometric force - time characteristics and agility performance, the following was established:

- Statistically significant relation was established between almost all force-time characteristics and the indicators of agility performance test (Table 2), from moderate to strong correlation

- The best correlation was between force-time characteristics with $T$ test from $r=-0.294, p=0.023$ for $\mathrm{RFD}_{250 \mathrm{~ms}}$ to $\mathrm{r}=-0.604, \mathrm{p}<0.001$ for $\mathrm{RFD}_{180 \mathrm{~ms}}$ (Table 2);

- In the case of the defensive movements test, the best correlation was between maximal force indicators and explosiveness and neuromuscular function of legs extensors measured at $180 \mathrm{~ms} r=-0.517, p<0.001$ for $F_{\max }, r=-0.531, p<0.001$ for $R F D_{\text {Fmax }}$ and $r=-0.510, p<0.001$ for $\mathrm{RFD}_{180 \mathrm{~ms}}$ (Table 2);

- In the case of the Slalom and Slalom with ball test the best correlation was between the indicators of neuromuscular functions of the leg extensors, measured at $180 \mathrm{~ms}, \mathrm{r}=-0.493, \mathrm{p}<0.001$ for $\mathrm{RFD}_{180 \mathrm{~ms}}$ in slalom without ball and $r=-0.473, p<0.001$ for $\mathrm{RFD}_{180 \mathrm{~ms}}$ in slalom with ball test (Table 2);

- In the case of Change of direction with and without dribbling test the best correlation was between the indicators of 
maximal force and explosiveness and neuromuscular function of leg extensors, measured at $180 \mathrm{~ms}, \mathrm{r}=-0.519$, $p<0.001$ for $F_{\max }$ and $r=-0.453, p<0.001$ for $R_{F D} 180 \mathrm{~ms}$ in Change of direction without dribbling and $r=-0.610, p<0.001$ for $F_{\max }$ and $r=-0.545, p<0.001$ for $R_{F D} D_{180 m s}$ in Change of direction with dribbling test (Table 2);

- In the case of Control of dribbling test the best correlation was between the indicators of maximal force and explosiveness, $r=-0.568, p<0.001$ for $F_{\max }$ and $r=-0.584, p<0.001$ for $\operatorname{RFD}_{\text {Fmax }}$ (Table 2).

From the aspect of absolute isometric force-time characteristics and speed performace, the following was established:

- Statistically significant relation was established between almost all force-time characteristics and the indicators of speed performance test (Table 3); from moderate to strong correlation;

- The best indicators of starting performance (time to $5 \mathrm{~m}$ Quickness $5 \mathrm{~m}$ ) included maximum force and rate of force development generated on $180 \mathrm{~ms}, r=-0.345, p=0.007$ for $F_{\max }$ and $r=-0.320, p=0.013$ for $R_{F D}{ }_{180 \mathrm{~ms}}$ in Quickness $5 \mathrm{~m}$ and $r=-0.369, p=0.004$ for $R_{F D} D_{\text {max }}$ and $r=-0.368, p=0.004$ for RFD180ms in Quickness with ball $5 \mathrm{~m}$ (Table 3):

- With Acceleration $15 \mathrm{~m}$ (with and without ball) the best correlation was between maximal force and explosiveness measured at $180 \mathrm{~ms}, r=-0.574, p<0.001$ for $F_{\max }$ and $r=-0.468, p<0.001$ for $R_{F D} D_{180 m s}$ in Acceleration $15 \mathrm{~m}$ and $r=-0.455, p<0.001$ for $F_{\max }$ and $r=-0.449$, $\mathrm{p}<0.001$ for $\mathrm{RFD}_{\mathrm{Fmax}}$ in Acceleration with ball $15 \mathrm{~m}$ (Table 3);

- The best predictors of maximum sprinting speed (Sprint 20 $\mathrm{m}$ with and without ball) included maximum force and rate of force development, $r=-0.544, p<0.001$ for $F_{\max }$ and $r=-0.460, p<0.001$ for $R_{F D} 180 \mathrm{~ms}$ in Sprint $20 \mathrm{~m}$ and $r=-0.495$, $p<0.001$ for $F_{\max }$ and $r=-0.462, p<0.001$ for $R_{F D} D_{\max }$ in Sprint with ball $15 \mathrm{~m}$ (Table 3).

Tables 4 and 5 show the results of relation between relative values of neuromuscular function of leg extensors and speed and agility performance.

From the aspect of relative isometric force - time characteristics and agility performance, the following was established:

- Statistically significant relation was established between all force-time characteristics and the indicators of agility performance test (Table 4); from moderate to strong correlation

- The best correlation was between force-time characteristics with $T$ test from $r=-0.457, p<0.001$ for $\mathrm{RFD}_{100 \mathrm{msallom}}$ to $\mathrm{r}=-0.622, \mathrm{p}<0.001$ for $\mathrm{RFD}_{250 \mathrm{msallom}}$ (Table 4);

- In the case of Defensive movements test the best correlation was between the indicators of maximal force and explosiveness $r=-0.562, p<0.001$ for Fallom, $r=-0.549$, $\mathrm{p}<0.001$ for $\mathrm{RFD}_{\text {allom }}$ (Table 4);

- In the case of Slalom and Slalom with ball test the best correlation was between the indicators of neuromuscular function of the leg extensors, measured at $250 \mathrm{~ms}, \mathrm{r}=-$ $0.526, p<0.001$ for $\mathrm{RFD}_{250 \mathrm{msallom}}$ in Slalom without ball and $r=-0.515, p<0.001$ for Fallom and $r=-0.531, p<0.001$ for $\mathrm{RFD}_{250 \mathrm{msallom}}$ in Slalom with ball test (Table 4);
- In the case of Change of direction with and without dribbling test the best correlation was between the indicators of neuromuscular leg extensors function measured at $50 \%$ of maximal force $r=-0.462, p<0.001$ for $\mathrm{RFD}_{50 \% \text { allom }}$ in Change of direction without dribbling $r=-0.554, p<0.001$ for $\mathrm{RFD}_{50 \% \text { allom }}$ in Change of direction with dribbling test (Table 4);

- In the case of Control of dribbling test the best correlation was between the indicators of maximal force and explosiveness $r=-0.532, p<0.001$ for $F_{\text {allom }}$ and $r=-0.592$, $\mathrm{p}<0.001$ for $\mathrm{RFD}_{\text {allom }}$ (Table 4).

From the aspect of relative isometric force-time characteristics and sprint performace, the following was established:

- Statistically significant relation was established between almost all relative force-time characteristics and the indicators of agility performance test (Table 5); from moderate to strong correlation;

- With Quickness $5 \mathrm{~m}$ (with and without ball) the best correlation was between maximal force and explosiveness measured at $250 \mathrm{~ms}$ and $50 \%$ of maximum, $r=-0.363, p=0.004$ for $R_{F D} D_{250 m s a l l o m}$ in Quickness $5 \mathrm{~m}$ and $\mathrm{r}=-0.336, \mathrm{p}=0.009$ for $\mathrm{RFD}_{50 \% \text { allom }}$ in Quickness with ball $5 \mathrm{~m}$ (Table 5);

- With Acceleration $15 \mathrm{~m}$ (with and without ball) the best correlation was between maximal force and explosiveness measured at $250 \mathrm{~ms}, \mathrm{r}=-0.591, \mathrm{p}<0.001$

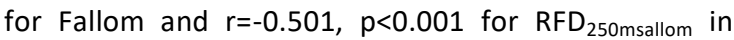
Acceleration $15 \mathrm{~m}$ and $\mathrm{r}=-0.513, \mathrm{p}<0.001$ for $\mathrm{F}_{\text {allom }}$ and $r=-0.480, p<0.001$ for RFD $_{\text {allom }}$ in Acceleration with ball $15 \mathrm{~m}$ (Table 5);

- With Sprint $20 \mathrm{~m}$ (with and without ball) the best correlation was between maximal force and explosiveness measured at $250 \mathrm{~ms}, r=-0.563, p<0.001$ for Fallom and $r=-0.501, p<0.001$ for $R^{2} D_{250 m s a l l o m}$ in Sprint $20 \mathrm{~m}$ and $r=-0.523, p<0.001$ for $F_{\text {allom }}$ and $r=-0.479$, $p<0.001$ for $\mathrm{RFD}_{\text {allom }}$ in Sprint with ball $15 \mathrm{~m}$ (Table 5 ).

\section{Discussion}

From the previous studies on the specificity of moving structure in competitive conditions and on defining time parameters for realizing the most characteristic motor tasks of movement techniques, the following typical time intervals can be isolated: $250 \mathrm{~ms}$ as the time necessary to perform the stretch-shortening cycle, $180 \mathrm{~ms}$ as the characteristic ground contact time during running in submaximal exertion regime, frequent changes of movement direction and vertical rebounds and $100 \mathrm{~ms}$ as ground contact time during running in absolute maximal intensity $[11,13,15,19]$. Elite athletes need 50 to $250 \mathrm{~ms}$ to perform fast moves, while in order to develop absolute muscle force in most muscle groups, they need more time ( $300 \mathrm{~ms}$ for the elbow flexors and knee extensors) [13]. Therefore, every increase of RFD in the specific time interval is highly significant because it provides high-level intensity of force development in the early phase of muscle contraction (first 100-200 ms), i.e. consequently efficient and faster motoric performance. As the performance increases, the phenomenon of the intensification of the sports competition (game or race performance) can be observed, which consequently increases the movement speed, that is, decreases the time needed to perform the elements of technique, the role of specific characteristics of maximal and explosive force [19]. 
Table 4. Relation between relative values of neuromuscular function of leg extensors and agility performance

\begin{tabular}{|c|c|c|c|c|c|c|}
\hline & $\mathrm{F}_{\text {allom }}$ & $\mathrm{RFD}_{\text {allom }}$ & $\mathrm{RFD}_{50 \% \text { allom }}$ & $\mathrm{RFD}_{100 \mathrm{msallom}}$ & $\mathrm{RFD}_{180 \mathrm{msallom}}$ & $\mathrm{RFD}_{250 \mathrm{msallom}}$ \\
\hline$T$ test forward running & $-0.531 * *$ & $-0.500 * *$ & $-0.543^{* *}$ & $-0.428 * *$ & $-0.544^{* *}$ & $-0.569 * *$ \\
\hline $\mathrm{T}$ test lateral running & $-0.557 * *$ & $-0.473 * *$ & $-0.616 * *$ & $-0.479 * *$ & $-0.587 * *$ & $-0.609 * *$ \\
\hline $\mathrm{T}$ test backward running & $-0.421 * *$ & $-0.297^{*}$ & $-0.312^{*}$ & -0.188 & $-0.333 * *$ & $-0.386 * *$ \\
\hline $\mathrm{T}$ test totally & $-0.585^{* *}$ & $-0.492 * *$ & $-0.603 * *$ & $-0.457^{* *}$ & $-0.589 * *$ & $-0.622 * *$ \\
\hline Defensive movements & $-0.562 * *$ & $-0.549 * *$ & $-0.488 * *$ & $-0.352 * *$ & $-0.484 * *$ & $-0.524 * *$ \\
\hline Slalom & $-0.482 * *$ & $-0.445 * *$ & $-0.510 * *$ & $-0.386 * *$ & $-0.495 * *$ & $-0.526 * *$ \\
\hline Slalom with dribbling & $-0.515^{* *}$ & $-0.473 * *$ & $-0.503 * *$ & $-0.380 * *$ & $-0.486 * *$ & $-0.531 * *$ \\
\hline Change of direction & $-0.556 * *$ & $-0.420 * *$ & $-0.462 * *$ & $-0.361 * *$ & $-0.446 * *$ & $-0.466 * *$ \\
\hline Change of direction with dribbling & $-0.628 * *$ & $-0.498 * *$ & $-0.554 * *$ & $-0.437 * *$ & $-0.542 * *$ & $-0.573 * *$ \\
\hline Control of dribbling & $-0.598 * *$ & $-0.558 * *$ & $-0.592 * *$ & $-0.471 * *$ & $-0.548 * *$ & $-0.584 * *$ \\
\hline
\end{tabular}

Data presented as Pearson correlation coefficient. ${ }^{*} \mathrm{p}<0.05 ; * * \mathrm{p}<0.01$

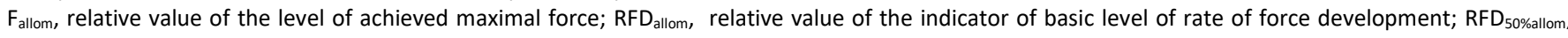
relative value of $S$ gradient; $R F D_{100 m s a l l o m}$, relative value of rate of force development measured at 100 ms; $R F D_{180 m s a l l o m}$, relative value of rate of force development measured at 180 ms; RFD 250 mallom, relative value of rate of force development measured at $250 \mathrm{~ms}$.

Table 5. Results of relation between relative values of neuromuscular function of leg extensors and speed performance

\begin{tabular}{|c|c|c|c|c|c|c|}
\hline & $\mathrm{F}_{\text {allom }}$ & $\mathrm{RFD}_{\text {allom }}$ & $\mathrm{RFD}_{50 \% \text { allom }}$ & RFD $_{100 \text { msallom }}$ & $\mathrm{RFD}_{180 \mathrm{msallom}}$ & $\mathrm{RFD}_{250 \mathrm{msallom}}$ \\
\hline Quickness 5m & $-0.360 * *$ & -0.177 & -0.251 & -0.115 & $-0.310^{*}$ & $-0.363^{* *}$ \\
\hline Acceleration $15 \mathrm{~m}$ & $-0.591 * *$ & $-0.423^{* *}$ & $-0.461 * *$ & $-0.322 *$ & $-0.466 * *$ & $-0.501 * *$ \\
\hline Sprint $20 \mathrm{~m}$ & $-0.563^{* *}$ & $-0.369 * *$ & $-0.426 * *$ & $-0.273^{*}$ & $-0.455^{* *}$ & $-0.501 * *$ \\
\hline Quickness with ball $5 \mathrm{~m}$ & $-0.348 * *$ & $-0.305^{*}$ & $-0.336 * *$ & -0.247 & $-0.314^{*}$ & $-0.312^{*}$ \\
\hline Acceleration with ball $15 \mathrm{~m}$ & $-0.513^{* *}$ & $-0.480 * *$ & $-0.416 * *$ & $-0.266^{*}$ & $-0.397 * *$ & $-0.437 * *$ \\
\hline Sprint with ball $20 \mathrm{~m}$ & $-0.523^{* *}$ & $-0.479 * *$ & $-0.451 * *$ & $-0.309 *$ & $-0.426 * *$ & $-0.450 * *$ \\
\hline
\end{tabular}

Data presented as Pearson correlation coefficient. ${ }^{*} \mathrm{p}<0.05 ;{ }^{*} \mathrm{p}<0.01$.

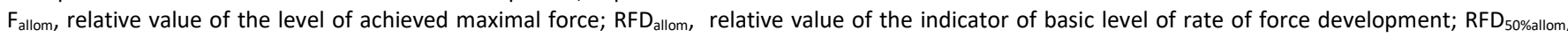
relative value of $\mathrm{S}$ gradient; $\mathrm{RFD}_{100 \mathrm{msallom}}$, relative value of rate of force development measured at $100 \mathrm{~ms}$; $\mathrm{RFD} \mathrm{D}_{180 \mathrm{msallom}}$, relative value of rate of force development measured at $180 \mathrm{~ms} ; \mathrm{RFD}_{250 \mathrm{msallom}}$, relative value of rate of force development measured at $250 \mathrm{~ms}$.

In the case of speed tests (Tables 3 and 5), the results of previous studies $[11,12]$ strongly support our findings. The results of these studies support the fact that strength qualities such are the rate of force development or force exerted in the early phase of muscle contraction might be more important than maximal strength, because sprinting involves efforts of short duration. Also based on the results of these studies strength expressed relative to body mass was more strongly related to sprint ability. Our results support this notion in terms of the importance of relative strength and idea that relative strength is a better predictor of movement performance than absolute strength $[21,25]$ (Tables 4 and 5).

Based on obtained results, the special level of explosiveness development measured at $180 \mathrm{~ms}\left(\mathrm{RFD}_{180 \mathrm{~ms}}\right)$ had the best correlation with the values of the observed characteristics in field tests (Tables $2-5)$. Besides, it's clear that maximal force $\left(F_{\max }\right)$ is distinguished as a good indicator of almost all speed and agility performances in basketball players (Tables 2-5). From the practical point of view, it means that the participant who had a highly developed maximal force (basic contractile property - level of muscle force exertion, realized in isometric conditions, as an indicator of general fitness level) and indicator of the special level of explosive force development, measured at $180 \mathrm{~ms}$ of $\mathrm{t}_{\mathrm{Fmax}}$ (the indicator of directed and specific fitness level from the aspect of muscle force exertion), did have a proportionally developed performance ability such as speed and agility. These results indirectly confirm the results of previous research [5], which defined characteristics of relation between maximal muscle force achieved in isometric conditions and different characteristics of explosive force development. Based on obtained results, from the tested male sample, it was concluded that the ability of maximal force exertion and intensity of its exertion in the time unit, i.e. basic explosive force, haven't had any statistically significant connection. However, the correlation between maximal force and both specific and special indicators of explosive force, in regard to tested male sample, has showed that the given connection was statistically significant. From the practical point of view this means that the statistically significant relation between maximal muscle force and the indicators of explosive force realized in time intervals of $50 \%$ of $F_{\max }, 250 \mathrm{~ms}, 180$ and $100 \mathrm{~ms}$, i.e. in the early phases of muscle contractions, was functionally strong and physiologically dependent. It seems that the level of exerted muscle force had the crucial influence on the resultant force-time conditionality, i.e. explosive muscle force at all levels of development. By that fact alone, the results of our previous study [5] were confirmed. Those results showed that from the aspect of training technology, the combination of maximal exertion methods, with the purpose of maximal force or strength development, with plyometryc in the purpose of contraction intensity development in its early stages, absolutely desirable and justified.

It's interesting to mention data of studies which determined that training of top level athletes combined in this way could improve speed and starting acceleration, and physical characteristics which rely on explosive force, powerful leg reaction during the rebound, sprint, maximal force production and time necessary to reach maximal force as well $[19,20]$. This kind of training activities could boost the speed of explosive-reactive type of movements. This specific training results in increasing the muscle force in time interval of $100 \mathrm{~ms}$ and $200 \mathrm{~ms}$, with the tendency of shifting the force-time curve towards the $100 \mathrm{~ms}$ peak. Also, the specific training model has improved the most relevant element - Stretch-Shortening cycle of Contraction, i.e. has shortened the time necessary to shift from concentric to eccentric muscle contraction, which synchronizes muscles units. 
Presumably, these results $[19,20]$ could explain somewhat surprising fact that the absolute values indicator of special level of explosive force development, measured at $250 \mathrm{~ms}$ of $t_{\mathrm{Fmax}}$ hasn ${ }^{\mathrm{t}} \mathrm{t}$ statistically significant correlated with the majority of agility and speed performances, contrary to the $\mathrm{S}$ gradient as a rate of force development measured at $50 \%$ of $\mathrm{F}_{\max }$ (Tables 2 and 3 ). According to results of this research, time necessary to achieve $50 \%$ of $F_{\max }$ was $0.207 \mathrm{~ms}$. Based on that, we can assume that specific basketball training process had impact and shortened the time necessary to shift from concentric to eccentric muscle contraction which synchronize muscle units, which confirmed the results of some other researches as well $[19,20]$.

Based on the obtained results, there is indication that muscular force and explosiveness from the aspect of absolute and relative values, might be important determinants of speed and agility performances and therefore worthwhile developing in the pursuit of improving these abilities. Additional research in the area of longitudinal changes in strength and performance ability is necessary to successfully understand causative relationships instead of only determining cross-sectional relationship. Besides, it's important to mention that we have tested young basketball players at the beginning of their preparation period in national selections and that they have been subjected to different training regimes in their clubs.

\section{Conclusion}

Among the measured force-time characteristics of leg extensors with the observed characteristics of performance tests, maximal force (as an indicator of basic fitness level) and the indicator of special level of explosive force development RFD ${ }_{180 \mathrm{~ms}}$ (as an indicator of directed and specific fitness level from the aspect of muscle force manifestation), measured at $180 \mathrm{~ms}$ of $t_{\text {Fmax }}$, appear to be the best indictors of speed and agility performances. Generally speaking, the obtained results indirectly confirm that diagnostics of the fitness level and the athletes selection in the domain of contractile abilities, which is controlled with basic parameters, i.e. with the level of maximal force development $\left(F_{\max }\right)$ or explosiveness $\left(\mathrm{RFD}_{\mathrm{Fmax}}\right)$ couldn't provide valid data on absolute training process control, therefore not enough data on optimization of the training process.

The practical implications of a moderate to strong and consistent correlation between neuromuscular function of leg extensors and characteristics of performance tests might indicate that improvements in force-time characteristics in young basketball players, may result in significant improvements in speed and change of direction performances longitudinally.

Based on the results from this study, it is recommended that tests for assessing neuromuscular function of leg extensors, like other fitness or physiological tests, should be in line with the concept of specificity. In order to diagnose the training level of basketball players and to provide absolute and valid data in the function of observing, controlling and optimizing the training process, among the basic indicators of the maximal force $\left(F_{\max }\right)$ development level, it is recommended to use specific and special characteristics of force-time characteristics of leg extensor in all explored time intervals as well as 250,180 and $100 \mathrm{~ms}$, and $50 \%$ of maximal force.

\section{Acknowledgments}

The paper was realized as part of project III47015 sponsored by Ministry of Science and Technological Development in the Republic of Serbia.

\section{Ethical approval}

All procedures performed in studies involving human participants were in accordance with the ethical standards of the institutional and/or national research committee and with the 1964 Helsinki declaration and its later amendments or comparable ethical standards.

\section{Conflict of interest}

The authors declare that they have no conflict of interest.

\section{References}

1. Copic N, Dopsaj M, Ivanovic J, Nesic G, Jaric S. Body composition and muscle strength predictors of jumping performance: Differences between elite female volleyball competitors and non-trained individuals. J Strength Cond Res 2014; 28(10): 2709-2716. https://dx.doi.org/10.1519/JSC.0000000000000468.

2. Delextrat A, Cohen D. Physiological testing of basketball players: toward a standard evaluation of anaerobic fitness. J Strength Cond Res 2008, 22(4): 1066-1072. https://dx.doi.org/10.1519/JSC.0b013e3181739d9b.

3. Drinkwater EJ, Pyne DB, McKenna MJ. Design and interpretation of anthropometric and fitness testing of basketball players. Sport Med 2008; 38(7): 565-578. https://doi.org/10.2165/00007256-20083807000004.

4. Ivanović J, Dopsaj M, Nešić G. Factor Structure differences of indicators for evaluating isometric leg extensors explosive force in female volleyball athletes and different trained female population. Br J Sports Med 2011; 45 : 542. https://dx.doi.org/10.1136/bjsm.2011.084558.26.

5. Ivanović J, Dopsaj M, Ćopić N, Nešić G. Is there a relation between maximal and explosive leg extensors isometric force? Facta Universitatis Series Physical Education and Sport 2011; 9(3): 239-254. http://facta.junis.ni.ac.rs/pe/pe201103/pe201103-03.pdf.

6. Jakovljević S, Karalejić M, Pajić Z, Macura M, Erčulj F. Speed and agility of 12 and 14 years old elite male basketball players. J Strength Cond Res 2012; 26(9): 2453-2459. https://dx.doi.org/10.1519/JSC.0b013e31823f2b22.

7. Dopsaj $\mathrm{M}$, Ivanović J. The analysis of the reliability and factorial validity in the basic characteristics of isometric F-t curve of the leg extensors in well trained Serbian males and females. Meas Sci Review 2011; 11(5): 165-172. https://doi.org/10.2478/v10048-011-0027-9.

8. Markovic $\mathrm{G}$. Poor relationship between strength and power qualities and agility performance. J Sports Med Phys Fitness 2007; 47(3): 276-283. https://www.ncbi.nlm.nih.gov/pubmed/17641593.

9. Augustsson J, Thomee R. Ability of closed and open kinetic chain test of muscular strength to assess functional performance. Scand J Med Sci Sports 2000; 10: 164-168. https://www.ncbi.nlm.nih.gov/pubmed/10843510.

10. Cronin JB, Hansen KT. Strength and power predictors of sports speed. $J$ Strength Cond Res 2005; 19(2): 349-357. https://doi.org/10.1519/14323.1.

11. Tillin NA, Pain MT, Foland J. Explosive force production during isometric squats correlates with athletic performance in rugby union players. J Sports Sci 2012; 31(1): 66-76. https://doi.org/10.1080/02640414.2012.720704.

12. Wisloff U, Castagna C, Helgerud J, Jones R, Hoff J. Strong correlation of maximal squat strength with sprint performance and vertical jump hight in elite soccer players. Br J Sports Med 2004; 38: 285-288. https://dx.doi.org/10.1136\%2Fbjsm.2002.002071.

13. Andersen LL, Aagaard P. Influence of maximal muscle strength and intrinsic muscle contractile properties on contractile rate of force development. Eur J Appl Physiol 2006; 96: 46-52. https://doi.org/10.1007/s00421-005-0070-z. 
14. Andersen LL, Andersen JL, Zebis MK, Aagaard P. Early and late rate of force development: differential adaptive responses to resistance training? Scand J Med Sci Sports 2010; 20(1): 162-169. https://dx.doi.org/10.1111/j.1600-0838.2009.00933.x.

15. Čoh M. Biomechanical characteristics of take off action in high jump a case study. Serbian Journal of Sports Sciences 2010; 4(4): 127-135.

16. Ivanović J, Dopsaj M. Reliability of force-time curve characteristics during maximal isometric leg press in differently trained high-level athletes. Measurement 2013; 46(7): 2146-2154. https://dx.doi.org/10.1016/j.measurement.2013.03.008.

17. Wilson G, Murphy A. Strength diagnosis: The use of test data to determine specific strength training. J Sports Sci 1996; 14(2): 167-173. https://dx.doi.org/10.1080/02640419608727698.

18. Karalejić M, Jakovljević $S$, Macura M. Anthropometric characteristics and technical skills of 12 and 14 year old basketball players. J Sports Med Phys Fitness 2011; 51: 103-110. https://www.ncbi.nlm.nih.gov/pubmed/21297570.

19. Zatsiorsky VM, Kraemer WJ. Science and practice of strength training. Champaign, IL: Human Kinetics, 2006; 98 p.

20. Rajić B, Dopsaj M, Abela CP. Basic and specific parameters of the explosive force of leg extensors in high trained Serbian female volleyball players: characteristics of the isometric force-time curve model. Serbian Journal of Sports Sciences 2008; 2(4): 131-139.

21. Jaric $S$. Role of body size in the relation between muscle strength and movement performance. Exerc Sport Sci Rev 2003; 31(1): 8-12. https://www.ncbi.nlm.nih.gov/pubmed/12562164.

22. Sheppard JM, Young WB. Agility literature review: classifications, training and testing. J Sports Sci 2006; 24(9): 919-932. https://dx.doi.org/10.1080/02640410500457109.

23. Lehmann G. Basketball is my Game. Lessons by Lehmann. NY: Riverside, 1981; $57 \mathrm{p}$.

24. Hopkins WG. A scale of magnitudes for effect statistics. A new view of statistics. [Internet]. 2011 [cited 2010 Apr 22]. http://www.sportsci.org/resource/stats.

25. Jaric $S$, Mirkov D, Markovic G. Normalizing physical performance tests for body size: A proposal for standardization. J Strength Cond Res 2005; 19(2): 467-474. https://dx.doi.org/10.1519/R-15064.1.

\section{Authors:}

Jelena Ivanović - PhD, Expert Adviser - Head of INDOC, Department of Development and Research Work in Sport, Serbian Institute of Sport and Sport Medicine, Belgrade, Serbia. https://orcid.org/0000-0002-9882-1813. Milivoj Dopsaj - PhD, Full Professor, Department of Analytic and Diagnostic in Sport, Faculty of Sport and Physical Education, Belgrade University, Belgrade, Serbia; Senior Researcher, Institute of Sport, Tourism and Service, South Ural State University, Chelyabinsk, Russia. https://orcid.org/0000-0001-7153-2993.

Saša Jakovljević - PhD, Dean, Full Professor, Department of Theory and Methodology of Basketball, Faculty of Sport and Physical Education, Belgrade University, Belgrade, Serbia. https://orcid.org/0000-0002-60129573.

Milivoje Karalejić - PhD, Full Professor, Department of Theory and methodology of Basketball, Faculty of Sport and Physical Education, Belgrade University, Belgrade, Serbia. https://orcid.org/0000-0002-0511$\underline{8687}$. 